\title{
(3) Protein Adsorption Switch Constructed by a Pillar[5]arene-Based Host-Guest Interaction
}

\author{
Xuan Xiao, Guanrong Nie, Xiaoyan Zhang, Demei Tian, and Haibing Li*[a]
}

Abstract: The interfacial properties of solid substrates are of importance for protein adsorption. Herein, we report a reversible protein adsorption switch based on the host-guest interaction of the butoxy pillar[5]arene and adipic acid. By the detector of the contact angle (CA), atomic force microscopy (AFM), and luminoscope on the silicon substrate, the intelligent protein switch exhibits excellent adsorptivity for BSA and switch performance by $\mathrm{pH}$ regulation.

\section{Introduction}

In recent years, macromolecular adsorption behavior on solid surfaces, ${ }^{[1]}$ especially protein adsorption, has drawn much attention because it plays a crucial role in medical, biological, and physiological processes, and exhibits wide application in the development of new biosensors, ${ }_{1}^{[2]}$ in immunological testing, ${ }^{[3]}$ and for drug delivery. ${ }^{[4]}$ Consequently, it is of interest to design featured surfaces for protein adsorption. For example, Wang et al., fabricated a gold surface with calix[4]arene derivatives that were designed to interact with proteins. ${ }^{[5]}$ Unfortunately, this research demonstrated that the self-assembled surface monolayer on the surfaces only realized irreversibly absorbed protein, and thus endowing these functional surfaces for more intelligent protein adsorption is still a challenging task. $\mathrm{pH}$-responsive switches on a functional surface undergo reversible changes in their properties when the solution is changed to an appropriate $\mathrm{pH}$. The protein adsorption on the surface is an important property of a solid material, ${ }^{[6]}$ which can be reversibly changed between hydrophobic and hydrophilic states by regulation of $\mathrm{pH}$. In this work, we extend surface functionalization for protein adsorption using a reversible host-guest interaction approach. Pillar[n]arenes $(n=5,6)$ represent a new family of paracyclophanes and exhibit unique inclusion properties. $^{[7]}$ Pillararenes can selectively bind a range of guests and provide a new platform for the construction of intelligent switches ${ }^{[8]}$ In recent years, many intelligent molecular machines, based on a host-guest system, have been designed to activate based on external stimuli, such as $\mathrm{pH}^{\left[{ }^{[0]}\right.}$ electricity, ${ }^{[10]}$ or light. ${ }^{[11]}$ Pillar[5]arene functionalized with decaamine can strongly bind linear $\alpha, \omega$-diacids that are six to 20 carbon

[a] X. Xiao, G. Nie, X. Zhang, D. Tian, Prof. H. Li

Key Laboratory of Pesticide and Chemical Biology (CCNU)

Ministry of Education, College of Chemistry

Central China Normal University, Wuhan 430079 (P.R. China)

E-mail:Ihbing@mail.ccnu.edu.cn

$\square$ Supporting information for this article is available on the WWW under http://dx.doi.org/10.1002/chem.201504076. atoms in length by hydrophobic and electrostatic interactions. $^{[12]}$

In addition, protein adsorption is a multifaceted process, which is mainly affected by the nature of the hydrophobic interactions and electrostatic effects. ${ }^{[13]}$ To realize the intelligent protein adsorption, we designed a new pillar[5]arene with butoxy functional groups (WP5) on the upper rim, ${ }^{[14]}$ which serves as the binding unit for proteins, whereas the cavity is used for the reversible assembly and disassembly with surface guests. To construct the intelligent switch, the surface was first modified with the guest molecule adipic acid (AA). The WP5 solution was then added to the surface, which was modified with AA under $\mathrm{pH}$ 3. The AA-WP5 host-guest complex spontaneously formed under those conditions, before protein adsorption was achieved by a hydrophobic interaction with the butoxy groups of the WP5. ${ }^{[15]}$ Finally, the protein was desorbed from the surface through an increase in solution $\mathrm{pH}$ to 11 , which resulted in the disassembly of the host-guest system.

\section{Results and Discussion}

The synthetic strategy for WP5 is depicted in Scheme 1. Hydroquinone $5.50 \mathrm{~g}$ (50 mmol) and potassium carbonate $13.80 \mathrm{~g}$ $(100 \mathrm{mmol})$ were stirred in refluxing acetonitrile for $0.5 \mathrm{~h}$, and then $n$-butyl bromide $13.70 \mathrm{~g}$ (100 mmol) was added. The mixture was stirred at $100^{\circ} \mathrm{C}$ for $10 \mathrm{~h}$, and the reaction liquid was poured into ice water, and then neutralization of excess alkali was carried out with dilute $\mathrm{HCl}$ to give the solid product. The crude product was purified by recrystallization to give 1,4-dibutoxy benzene as a white powder in $77.0 \%$ yield. Subsequently, 1,4-dibutoxy benzene $2.22 \mathrm{~g}(10 \mathrm{mmol})$ and paraformaldehyde $(\mathrm{HCHO})_{n} 8.5 \mathrm{~g}(30 \mathrm{mmol})$ were stirred in refluxing $\mathrm{CHCl}_{3}$ for $3 \mathrm{~h}$ under nitrogen protection and then $\mathrm{FeCl}_{3}$ $(0.243 \mathrm{~mL}, 1.5 \mathrm{mmol})$ was added, and the crude product was purified by column chromatography to give butoxy pillar[5]arene in $31.0 \%$ yield.

The target molecule, WP5, was synthesized by the strategy depicted in Scheme S1 (Supporting Information) and was characterized by ${ }^{1} \mathrm{H}$ and ${ }^{13} \mathrm{C}$ NMR spectroscopy (detailed in Figur- 


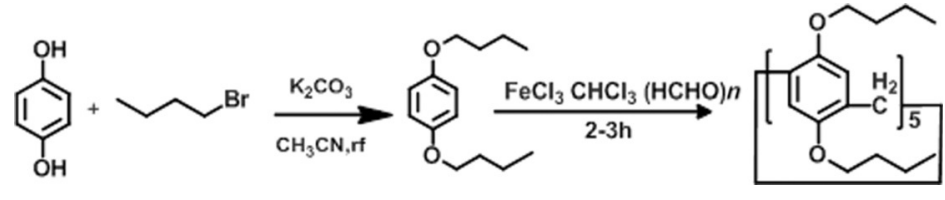

Scheme 1. Synthesis of WP5.

es S1 and S2, Supporting Information).To demonstrate that WP5 is able to observe reversible assembly and disassembly with $\mathrm{AA}$ by $\mathrm{pH}$ regulation, the process was followed by ${ }^{1} \mathrm{H}$ NMR spectroscopy. After AA had been added to a solution of WP5, chemical shift changes for the proton resonances of both WP5 and AA were observed. As shown in Figure 1 and Figure S4 (Supporting Information), the methylene AA peak at

(a)
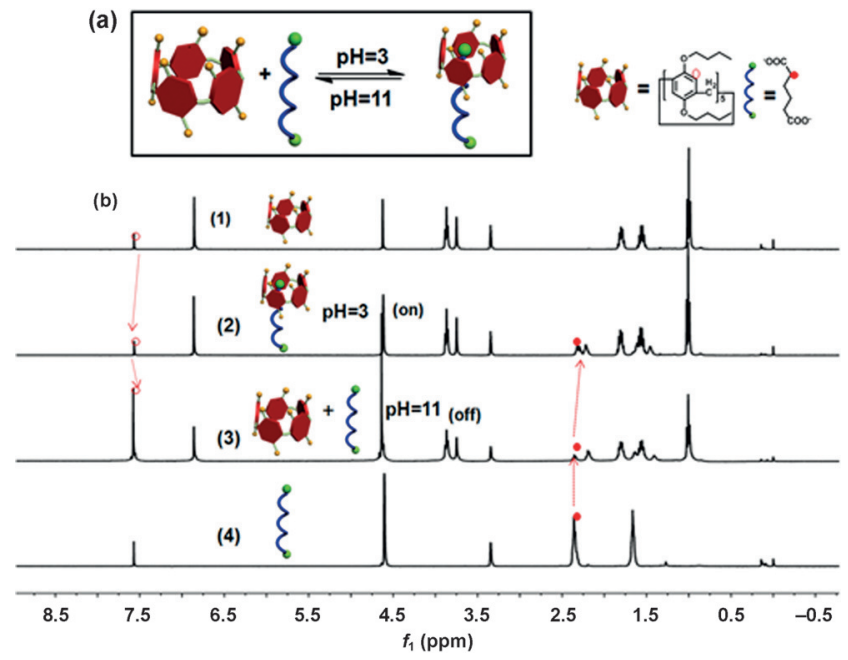

Figure 1. a) Schematic representation of the WP5 and AA self-assembled host-guest system. b) ${ }^{1} \mathrm{H}$ NMR spectra showing: 1) free WP5, 2) WP5 and AA $(\mathrm{pH} 3), 3)$ the AA and WP5 after the addition of $\mathrm{NaOH}(\mathrm{pH} \mathrm{11)}$, and 4) free $A A$, which shows that WP5 can bind reversibly to $A A$ and that the process is reversible upon an increase in $\mathrm{pH}\left(6 \mathrm{~mm}, \mathrm{CDCl}_{3}: \mathrm{CD}_{3} \mathrm{OD}=3: 1,400 \mathrm{MHz}\right.$, 298 K).

$\delta=2.36 \mathrm{ppm}$ shifts upfield to $\delta=2.31 \mathrm{ppm}$, while the aromatic peak of WP5 shifts downfield by $\delta=0.02 \mathrm{ppm}$, which suggests that AA binds within the cavity of WP5. When the $\mathrm{pH}$ value was changed to 11 , by the addition of $\mathrm{NaOH}$, the chemical shifts of the WP5 and AA peaks returned to their original values, which is consistent with the disassembly of the WP5 and AA host-guest complex. Here, we defined that the assembled state of the WP5 and the AA is "on" and the disassembled state is "off". To further demonstrate the host-guest complex formation, the electrospray ionization mass spectrum is shown in Figure S3, Supporting Information. The spectrum shows a molecular-ion peak at $\mathrm{m} / \mathrm{z}: 1339.300$ that is exactly equal to the calculated molecular mass for WP5, AA, and a sodium ion.

Based on the interaction between the WP5 and AA, a pH-responsive silicon surface was constructed (Figure S7a, Supporting Information). The silicon surface was prepared using a plasma deep-etching technique of a flat silicon wafer to create square pillars $20 \mu \mathrm{m}$ high, $9 \mu \mathrm{m}$ long and with an interpillar spacing of $12 \mu \mathrm{m}$ (Figure S5, Supporting Information). Next, the surface was modified with 3aminopropyltrimethoxysilane $\left(\mathrm{Si}-\mathrm{NH}_{2}\right)$, then $\mathrm{AA}$ was chemically attached to the solid surface by a classical $\mathrm{EDC} / \mathrm{NHS}$ coupling reaction. Finally, the reversible surface was assembled by addition of WP5 at pH 3 and disassembled at $\mathrm{pH} 11$. To verify the successful synthesis of the reversible surface, its performance was studied by contact angle (CA) analysis. As shown in Figure $2 \mathrm{a}$ and Figure S7b (Supporting Information), the bare silicon wafer was superhydrophilic, with the CA increasing to $25.1 \pm 2.0^{\circ}$ upon

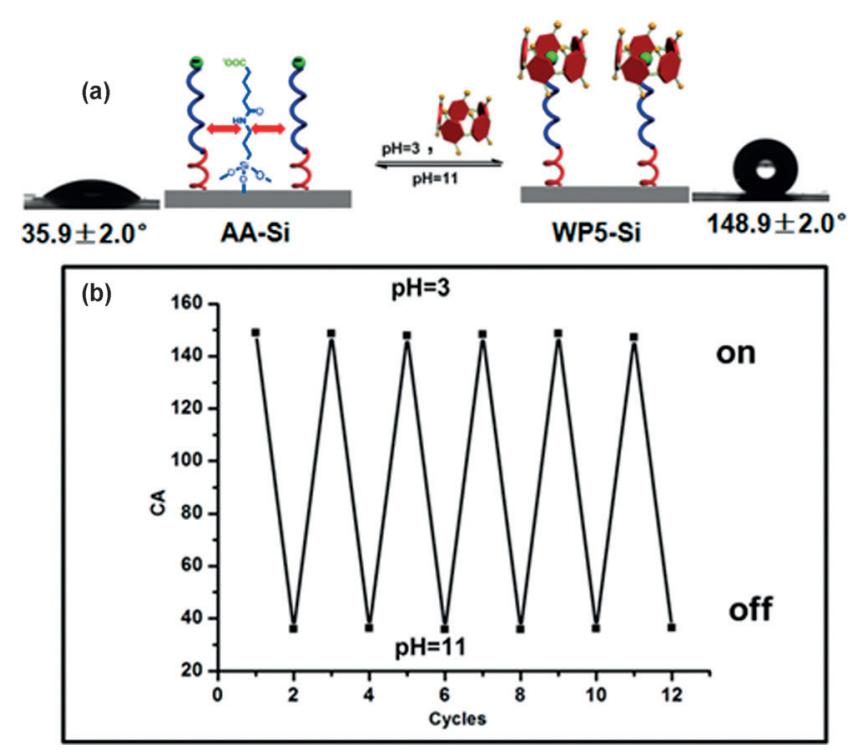

Figure 2. a) The WP5 and AA self-assembled host-guest system on a silicon interface. b) Cycling CAs between basic and acid environments, showing six cycles between the hydrophilic and hydrophobic states, confirming the $\mathrm{pH}$ responsive switching of the system.

the fixation of $\mathrm{Si}-\mathrm{NH}_{2}$ to the surface. Similarly, the CA continued to increase to $35.2 \pm 2.0^{\circ}$ after chemical attachment of AA. Afterwards, the adipic acid modified surface (AA-Si) was immersed in a $10^{-3} \mathrm{M}$ WP5 solution, at which point the CA increased further to $148.9 \pm 2.0^{\circ}$; a superhydrophobic state (defined as "on") that may be caused by the hydrophobic properties of WP5's n-butyl. The result, therefore, suggests that WP5 bound successfully to the silicon surface (WP5-Si) through encapsulation of AA within its cavity. When the WP5-Si surface was treated with a solution of $\mathrm{pH} 11$, the CA of the surface recovered to $35.9 \pm 2.0^{\circ}$; a hydrophilic state (defined as "off"), which is consistent with disassembly of the WP5 AA hostguest system. At the same time, we carried out SEM of WP5 $\supseteq A A$ complex before and after modification on the etching silicon surface (Figure S6, Supporting Information). Overall, the results demonstrate that the switch is reversible and can be controlled by adjusting solution $\mathrm{pH}$. As shown in Figure $2 \mathrm{~b}$, the switch can be turned off and on repeated times; six on/off cycles were undertaken by changing solution $\mathrm{pH}$. 
(a) AA-Si
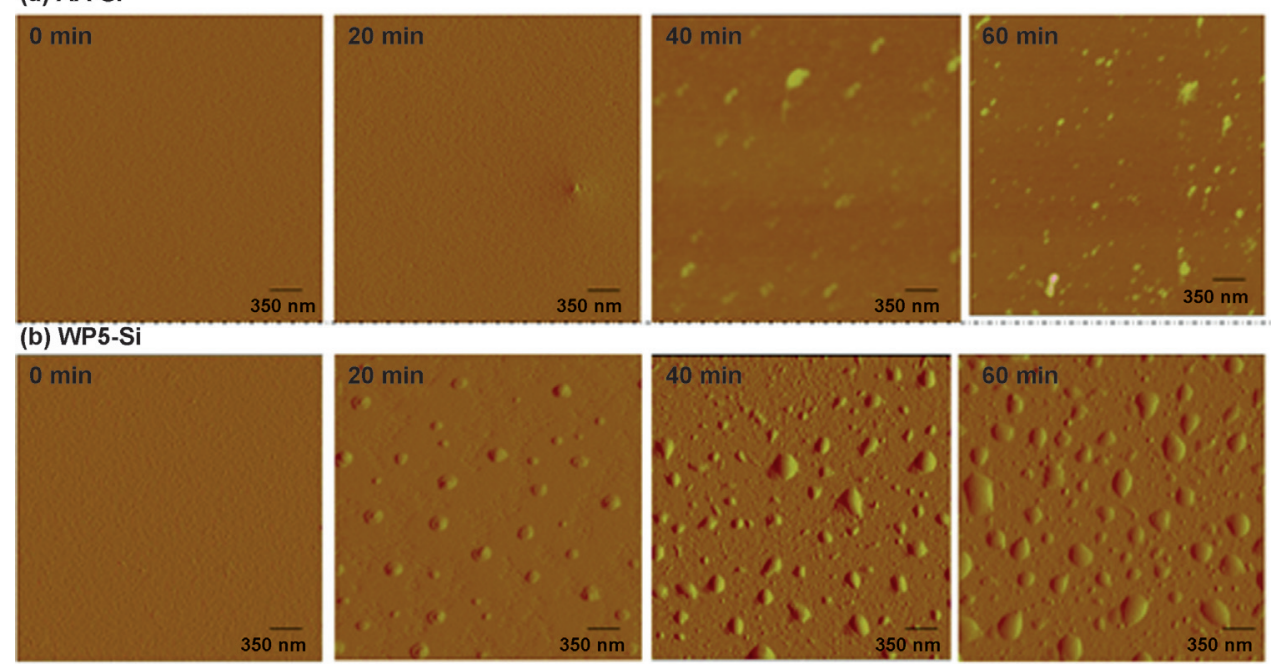

Figure 3. AFM characterization showing substrata topographic images obtained from the BSA adsorbed onto the substrata. a) Native (AA-Si) and b) after (WP5-Si) functionalized at different times, which indicates the difference between the "on" and "off" states for BSA absorption with time. Images $350 \times 350$ nm were first recorded under high load (z-range: $500 \mathrm{~nm}$ ) of the same substrata.

We next confirmed the feasibility of the host-guest system to act as a protein adsorption switch using fluorescence spectrophotometry. The functional silicon surface was placed in a cuvette filled with the protein, bovine serum albumin (BSA) for $1 \mathrm{~h}$, before the fluorescence intensity was measured. As can be seen in Figure S8a (Supporting Information), after immersing the adipic acid modified surface (AA-Si) in the BSA solution at $\mathrm{pH} 3$ for $1 \mathrm{~h}$, the fluorescence intensity for BSA adsorption was slightly reduced compared with a bare silicon surface control under the same conditions. Next, the pillar[5]arene-modified silicon surface (WP5-Si) was added into a BSA solution for $1 \mathrm{~h}$, and the fluorescence was measured. The result was a significant decrease in fluorescence intensity, which can be explained by a decrease in BSA concentration in solution as it is adsorbed on the WP5-Si surface. When the solution $\mathrm{pH}$ is adjusted to 11 , the fluorescence intensity nearly recovers to its initial value, which suggests that the BSA has been released from the silicon surface. We also investigated the repeatability and reversibility properties of the BSA adsorption switch. In a recycle experiment, the BSA adsorption switch was hardly affected after six on/off cycles by alternating pH (Figure S9, Supporting Information).

To further verify BSA adsorption onto the WP5-Si surface, experiments to examine fluorescence kinetics, and analysis by AFM and SEM, were carried out over various time periods. The results for the fluorescence kinetics test over a period of $1 \mathrm{~h}$ are shown in Figure $S 8 \mathrm{~b}$, Supporting Information. When the AA-Si was soaked in BSA solution, the fluorescence change of the solution versus time was close to a straight line compared with the control, which showed that BSA was not adsorbed on the AA-Si surface without WP5. In contrast, after the WP5-Si surface was soaked in BSA solution, the fluorescence intensity decreased gradually with the time and then remained constant after about $30 \mathrm{~min}$. To demonstrate the BSA adsorption pro- cess on the silicon surface, the WP5-Si was immersed in a solution of BSA for $0,10,20$, and 30 min, respectively, and then analyzed by AFM and SEM. As shown in Figure $3 \mathrm{~b}$, the AFM images show that the number of the granules increased, which indicates that BSA adsorption increased over time. In contrast, after the solution $\mathrm{pH}$ is increased to 11 , there are no observable granules by AFM, which indicates that BSA was not adsorbed on the surface. These results were also confirmed by SEM (Figure S11, Supporting Information). A significant difference was observed in the SEM images for BSA adsorption at $\mathrm{pH} 3$ and 11. The AA-Si surface does not significantly absorb any BSA, and thus, the SEM image did not change with time. However, the WP5-Si surface was observed to be covered with an increasing number of lumps as time progressed, which indicated that the quantity of BSA adsorbed onto the WP5-Si surface increased with time. Furthermore, we also compared the $C A$ value as a function of time. The results show a remarkable decrease of the CA as the WP5-Si adsorbed BSA over time (Figure S10, Supporting Information). In short, these experiments demonstrate that the WP5-Si surface can adsorb BSA at pH 3, and it releases from the surface at $\mathrm{pH} 11$.

We hypothesize that the hydrophobic pocket of BSA can interact with the hydrophobic alkyl chain of WP5 and the resulting interaction causes BSA to be absorbed from solution. However, our results indicate that electrostatic interactions ${ }^{[16]}$ do not contribute to BSA adsorption. This is because neither the WP5 nor AA-Si, which has a $\mathrm{pK}_{\mathrm{a}}$ of 3.8 , are charged in a solution of $\mathrm{pH}$ 3. Secondly, BSA adsorption on the WP5 surface is driven by hydrophobic interactions. The WP5-Si surface, which causes BSA adsorption, is superhydrophobic; this has been demonstrated through tests. However, the AA-Si surface is hydrophilic, which means no BSA is absorbed in the absence of WP5, which is consistent with our hypothesis that hydrophobic interactions drive the absorption of protein (Figure 4). 


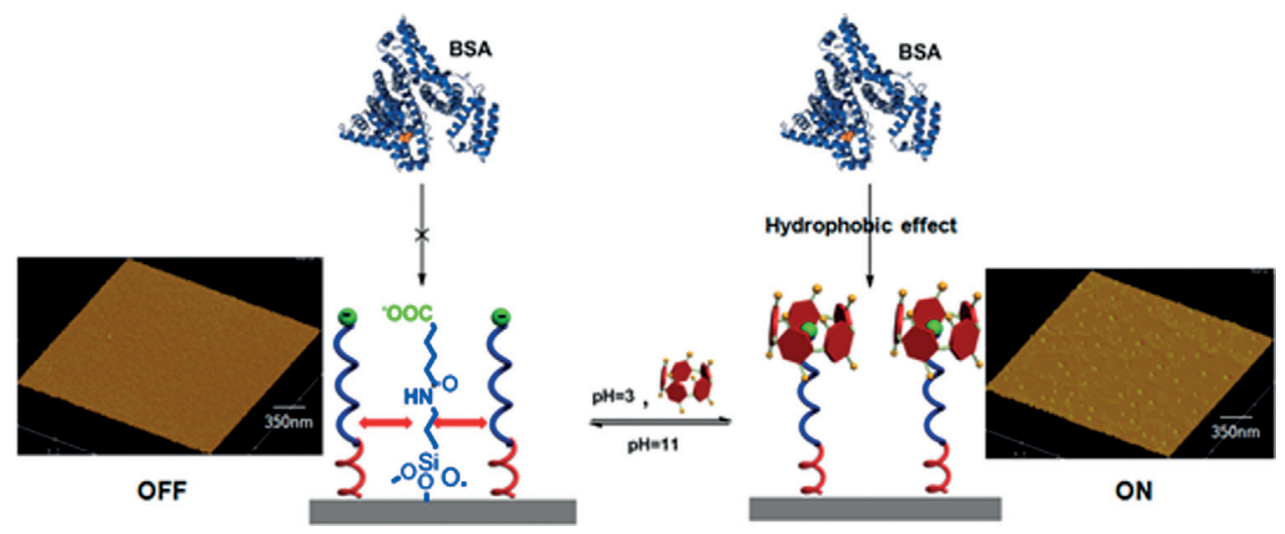

Figure 4. A new protein adsorption switch successfully designed to turn "on" and "off" by pH adjustment based on a reversible host-guest system of WP5 and AA.

\section{Conclusion}

A new protein adsorption, $\mathrm{pH}$-driven switch was successfully designed based on a reversible host-guest system of the butoxy pillar[5]arene and adipic acid. Characterization by ${ }^{1} \mathrm{H}$ NMR spectroscopy, fluorescence, ESI-MS, AFM, and SEM, showed that the WP5 surface exhibited not only favorable adsorption of BSA, but that the BSA adsorption could be switched by adjusting the $\mathrm{pH}$. As the protein absorption can be monitored using fluorescence spectrophotometry, our system many have wide application in the production of new biosensors, in immunological tests, and in drug delivery.

\section{Experimental Section}

\section{Synthetic method for butoxy pillar[5]arene}

The synthetic strategy for WP5 is depicted in Scheme 1. Hydroquinone $5.50 \mathrm{~g}(50 \mathrm{mmol})$ and potassium carbonate $13.80 \mathrm{~g}$ $(100 \mathrm{mmol})$ were stirred in refluxing acetonitrile for $0.5 \mathrm{~h}$, and then $n$-butyl bromide $13.70 \mathrm{~g}(100 \mathrm{mmol})$ was added. The mixture was stirred at $100^{\circ} \mathrm{C}$ for $10 \mathrm{~h}$. After the reaction was finished, the reaction liquid was poured into ice water and then dilute $\mathrm{HCl}$ was added to neutralize excess alkali to gain solid product. The crude product was purified by recrystallization to give 1,4-dibutoxy benzene as a white powder in $77.0 \%$ yield. Subsequently, 1,4-dibutoxy benzene $2.22 \mathrm{~g}(10 \mathrm{mmol})$ and paraformaldehyde $(\mathrm{HCHO}) n 8.5 \mathrm{~g}$ (30 mmol) were added and stirred while refluxing in $\mathrm{CHCl}_{3}$ for $3 \mathrm{~h}$ under nitrogen protection, and then $\mathrm{FeCl}_{3} 0.243 \mathrm{~mL}(1.5 \mathrm{mmol})$ was added. The crude product was purified by column chromatography to give butoxy pillar[5]arene in $31 \%$ yield. ${ }^{1} \mathrm{H}$ NMR $\left(\mathrm{CDCl}_{3}\right.$, $600 \mathrm{MHz}, 298 \mathrm{~K}): \delta=0.96-0.98\left(\mathrm{t}, 30 \mathrm{H}, \mathrm{CH}_{3}\right), 1.51-1.55(\mathrm{~m}, 20 \mathrm{H}$, $\left.\mathrm{CH}_{2}\right), 1.75-1.79\left(\mathrm{~m}, 20 \mathrm{H}, \mathrm{CH}_{2}\right), 3.75\left(\mathrm{~s}, 10 \mathrm{H}, \mathrm{CH}_{2}\right.$-bridge $), 3.84-3.86$ $\left(\mathrm{t}, 20 \mathrm{H}, \mathrm{O}-\mathrm{CH}_{2}\right), 6.83 \mathrm{ppm}(\mathrm{s}, 10 \mathrm{H}, \mathrm{Ar}-\mathrm{H}) ;{ }^{13} \mathrm{C} \mathrm{NMR}\left(150 \mathrm{MHz}, \mathrm{CDCl}_{3}\right)$ : $\delta=13.04\left(\mathrm{CH}_{3}\right), 18.52\left(\mathrm{CH}_{2}\right), 31.06\left(\mathrm{CH}_{2}\right), 36.6\left(\mathrm{CH}_{2}\right.$-bridge $), 66.90$ $\left(\mathrm{O}-\mathrm{CH}_{2}\right), 113.77(\mathrm{Ar}-\mathrm{H}), 127.09(\mathrm{Ar}-\mathrm{O}), 149.77 \mathrm{ppm}(\mathrm{Ar}-\mathrm{O}) ; \mathrm{MS}: \mathrm{m} /$

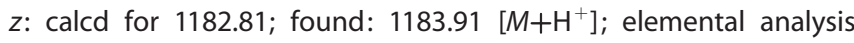
(\%) (found: C 77.28, H 9.26; WP5 requires C 77.12, H 9.37).

\section{Modification process}

The etched silicon was soaked in chromic acid lotion for about $2 \mathrm{~h}$, to remove organic matter on the silicon surface. After that, the cleaned silicon wafer was soaked in $0.1 \mathrm{M} \mathrm{NaOH}$ solution for $2 \mathrm{~min}$ and was then put into the nitric acid solution of $0.1 \mathrm{M}$ for $10 \mathrm{~min}$ to generate hydroxyl. Finally, the silicon wafer was washed with distilled water and was then blown dry by nitrogen to reserve. The preprocessed silicon wafer was modified with the $\mathrm{Si}-\mathrm{NH}_{2}$ in a methanol solution of $5 \mathrm{wt} \% \mathrm{SiNH}_{2}$ under reflux for $6 \mathrm{~h}$ at $60^{\circ} \mathrm{C}$. Then, the silicon chip was washed with methanol to remove the unreacted $\mathrm{Si}-\mathrm{NH}_{2}$. Subsequently, the adipic acid was fixed on the $\mathrm{Si}-\mathrm{NH}_{2}-$ modified silicon wafer by a classical EDC/NHS coupling reaction. During the process, amino silane-modified wafers continue to be immersed in the methanol solution containing $10^{-3} \mathrm{M} A \mathrm{~A}, \mathrm{EDC}$ $\left(10^{-3} \mathrm{M}\right)$, and five fluorine phenol $\left(10^{-3} \mathrm{M}\right)$ under $0^{\circ} \mathrm{C}$ for $24 \mathrm{~h}$. After this time, the silicon wafer was washed with methanol and blown dry by nitrogen. Ultimately, the butoxy pillar[5]arene was self-assembled in chloroform solution.

\section{Fluorescent assay}

To prove good pH-responsive properties of the host-guest system, fluorescent spectroscopic studies were carried out. The fluorescence kinetics experiment was measured in the BSA solution $(5 \times$ $10^{-5} \mathrm{M}$ ) in which the functioned surface was put. After the dynamic adsorption, the fluorescence intensity for the residual solution was put into effect. All the above fluorescent experiments were conducted by using the Agilent Cary Eclipse fluorescence system (Australia).

\section{Contact angles measurement}

The contact angles were measured using an OCA 20 contact angle system (Dataphysics, Germany), at $25^{\circ} \mathrm{C}$. After the modification of the silicon surface, the functional silicon surface was washed with the corresponding solvent, and was then blown dry by $\mathrm{N}_{2}$ before measuring the CA after every step of the modification.

\section{Acknowledgements}

This work was financially supported by the National Natural Science Foundation of China (21572076, 21372092), Natural Science Foundation of Hubei Province (2013CFA112, 2014CFB246), Wuhan Scientific and Technological Projects (2015020101010079), and self-determined research funds of 
CCNU from the colleges' basic research and operation of MOE (CCNU15KFY005).

Keywords: bovine serum albumin $\cdot$ host-guest systems $\cdot \mathrm{pH}$ reversible switch $\cdot$ pillar[5]arene $\cdot$ proteins

[1] a) J. D. Müller, M. Amrein, A. Engel, J. Struct. Biol. 1997, 119, 172; b) A Vinu, Carsten. Streb, V. Murugesan, M. Hartmann, J. Phys. Chem. B 2003, 107, 8297; c) H. X. Zhou, G. Rivas, A. P. Minton, Annu. Rev. Biophys. 2008 37, 375; d) I. Banerjee, R. C. Pangule, R. S. Kane, Adv. Mater. 2011, 23, 690 ; e) Q. Wei, T. Becherer, P. M. Noeske, I. Grunwald, R. Haag, Adv Mater. 2014, 26, 2688; f) V. O. Kollath, F. Van den Broeck, K. Fehr, J. C. Martins, J. Luyten, K. Traina, S. Mullens, R. Cloots, Chem. Eur. J. 2015, 21 10497; g) X. Hou, Y. H. Hu, A. Grinthal, M. Khan, J. Aizenberg, Nature 2015, 519, 70

[2] a) K. E. Sapsford, F. S. Ligler, Biosens. Bioelectron. 2004, 19, 1045; b) E. S Jeng, P. W. Barone, J. D. Nelson, M. S. Strano, Small 2007, 3, 1602; c) Q. Wei, T. Becherer, S. Angioletti-Uberti, J. Dzubiella, C. Wischke, A. T. Neffe, A. Lendlein, M. Ballauff, R. Haag, Angew. Chem. Int. Ed. 2014, 53, 8004 Angew. Chem. 2014, 126, 8138; d) K. Takasu, K. Kushiro, K. Hayashi, Y. Iwasakic, S. Inouec, E. Tamechikad, M. Takaia, Sens. Actuators B 2015 428; e) X. Hou, L. Jiang, ACS Nano 2009, 3, 3339.

[3] a) J. M. Peula-García, J. A. Molina-Bolivar, J. Velasco, A. Rojas, F. GalisteoGonzalez, J. Colloid Interface Sci. 2002, 245, 230; b) H. Dong, R. Nie, X Hou, P. Wang, J. Yue, L. Jiang, Chem. Commun. 2011, 47, 3102; c) X. H. Cheng, H. E. Canavan, D. J. Graham, D. G. Castner, B. D. Ratner, Biointerphases 2006, 1, 61; d) W. H. Hu, Y. S. Liu, T. Chen, Y. Liu, C. M. Li, Adv. Mater. 2015, 27, 181.

[4] a) A. S. Zahr, D. V. Melgardt, M. V. Pishko, Langmuir 2005, 21, 403; b) C. C. Lin, A. T. Metters, Biomacromolecules 2008, 9, 789; c) J. Zhang, W. Sun, L. Bergman, J. M. Roseholm, M. Linden, G. J. Wu, H. Xu, H. C. Gu, Mater. Lett. 2012, 67, 379; d) X. Hou, Y. J. Liu, H. Dong, F. Yang, L. Li, L. Jiang, Adv. Mater. 2010, 22, 2440; e) G. C. Yu, Y. J. Ma, C. Y. Han, Y. Yao, G. P. Tang, Z. W. Mao, C. Y. Gao, F. H. Huang, J. Am. Chem. Soc. 2013, 135, 10310.

[5] a) H. Chen, F. Liu, F. Qi, K. Koh, K. Wang, Int. J. Mol. Sci. 2014, 15, 5496; b) X. Hou, H. C. Zhang, L. Jiang, Angew. Chem. Int. Ed. 2012, 51, 5296; Angew. Chem. 2012, 124, 5390.
[6] a) Y. Kong, F. Xia, M. H. Zhang, X. Hou, Z. Y. Liu, J. Zhai, L. Jiang, ACS Appl. Mater. Interfaces 2013, 5, 7931; b) X. Hou, W. Guo, L. Jiang, Chem. Soc. Rev. 2011, 40, 2385.

[7] a) J. Cao, Y. Shang, B. Qi, X. Z. Sun, L. Zhang, H. W. Liu, H. B. Zhang, X. H. Zhou, RSC Adv. 2015, 5, 9993; b) T. Ogoshi, T. Yamagishi, Chem. Commun. 2014, 50, 4776; c) Y. Y. Yuan, C. Q. Mao, X. J. Du, J. Z. Du, F. Wang, J. Wang, Adv. Mater. 2012, 24, 5476.

[8] N. L. Strutt, H. Zhang, S. T. Schneebeli, J. F. Stoddart, Acc. Chem. Res. 2014, 47, 2631.

[9] a) Q. P. Duan, Y. Cao, Y. Li, X. Y. Hu, T. X. Xiao, C. Lin, Y. Pan, L. Y. Wang, J. Am. Chem. Soc. 2013, 135, 10542; b) S. Angelos, Y. W. Yang, K. Patel, J. F. Stoddart, J. I. Zink, Angew. Chem. Int. Ed. 2008, 47, 2222; Angew. Chem. 2008, 120, 2254.

[10] a) E. Gallicchio, M. Lapelosa, R. M. Levy, J. Chem. Theory Comput. 2010 6, 2961; b) J. E. Elenewski, J. C. Hackett, J. Phys. Chem. B 2010, 114, 11315.

[11] a) X. Y. Zhang, H. Y. Zhao, D. M. Tian, H. T. Deng, H. B. Li, Chem. Eur. J. 2014, 20, 9367; b) G. Pouliquen, C. Amiel, C. Tribet, J. Phys. Chem. B 2007, 111, 5587.

[12] a) X. B. Hu, L. Chen, W. Si, Y. H. Yu, J. L. Hou, Chem. Commun. 2011, 47, 4694; b) A. C. McUmber, T. W. Randolph, D. K. Schwartz, J. Phys. Chem. Lett. 2015, 6, 2583; c) X. Hou, H. Dong, D. B. Zhu, L. Jiang, Small 2010, 6, 361 .

[13] a) K. L. Prime, G. M. Whitesides, Science 1991, 252, 1164; b) V. Silin, H. Weetall, D. J. Vanderah, J. Colloid Interface Sci. 1997, 185, 94; c) R. D. Tilton, C. R. Robertson, A. P. Gast, Langmuir 1991, 7, 2710; d) M. J. W. Ludden, A. Mulder, R. Tampé, D. N. Reinhoudt, J. Huskens, Angew. Chem. Int. Ed. 2007, 46, 4104; Angew. Chem. 2007, 119, 4182.

[14] M. Xue, Y. Yang, X. D. Chi, Z. B. Zhang, F. H. Huang, Acc. Chem. Res 2012, 45, 1294.

[15] a) K. Farkas, A. Varsani, L. P. Pang, Food Environ. Virol. 2014, 7, 261; b) S. Mauri, M. Volk, S. Byard, H. Berchtold, H. Arnolds, Langmuir 2015, 31, 8892

[16] a) A. Rubinstein, S. Sherman, Biopolymers 2007, 87, 149; b) M. Van der Veen, W. Norde, M. C. Stuart, Colloids Surf. B 2004, 35, 33.

Received: October 11, 2015

Published online on December 3, 2015 